\title{
Editorial
}

\section{El Banco de la República y la fluctuación de la tasa cambio: ¿pasividad o shock externo?}

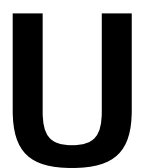

no de los problemas más preocupantes, desdeel punto de vista macr oeconómico, en los últimosaños, ha sido, sin duda, el comportamiento del tipo de cambio. Con relación al manejo del mismo, existen dos vertientes inter pr etativas: Ocampo, Cabrera y Sarmiento, plantean quela intervención del Banco de la República ha sido insuficiente, dado queno ha actuado de for ma decidida para evitar la elevada revaluación, pese a que tiene muchas posibilidades para hacer lo. De otra parte, Ortega, M ontenegro y Caballero, sostienen que el Banco ha hecho lo razonable debido a queel comportamiento de la tasa de cambio obedece no a razones internas sino a factores externos.

En 2012, el peso colombiano fuela moneda más revaluada en América Latina frente al dólar $(8,85 \%)$. Ocupó el tercer lugar en el mundo, ya queen el primer puesto sesituó el zloty polaco $(11,37 \%)$ y en el segundo lugar, el florín húngaro $(10,03 \%)$. Lo anterior quier e decir quea principios del año en curso, la situación en materia cambiaria era muy complicada. Dehecho, la presión para que la Junta del Emisor aplicara los correctivos necesarios provenía de los exportadores, pero también de los ministros de Hacienda y de Agricultura, quienes argumentaban que los bienes colombianos eran más costosos y perdían competitividad. Señalaban, además, que de continuar en el nivel de apreciación del peso, se afectaría la generación deempleo, uno de los objetivos económicos másimportantes del actual Gobierno. Adicionalmente, los datos sobre el sector externo ameritaban aplicar correctivos urgentes: en 2012, las exportaciones totales crecieron en $6,3 \%$, mientras que las importaciones lo hicieron a un ritmo de $8 \%$.

De allí que el 28 de enero del presente año, la Junta Directiva del Banco de la República decidió adoptar una serie de medidas para evitar que el peso se apreciara más y poder alcanzar así una tasa de cambio de equilibrio, la que según el ministro de Hacienda, debería estar cercana a los \$.1950 por dólar. Los medios de comunicación, con el transcurrir del tiempo, la denominaron "el dólar Cárdenas". Las medidas aplicadas por el Emisor están centradas en: 1) aumento dela compra de divisas de 20 a 30 millones de dólares diarios, con el fin de disminuir la oferta de los mismos, y así presionar la el evación de la tasa de cambio; 2)reducción de la tasa de interés del 4,25 al $4 \%$. El descenso de la tasa de interés tendría como finalidad, poruna parte, acortar la diferencia entre la tasa interna y la externa (recordemos que ésta es cercana a cero), y así desestimular la entrada de capitales de corto plazo que también afecta el valor de la tasa de cambio; y, por otra, incentivar la inversión y, por ende, la producción, dado que esta última venía presentando un estancamiento. 
Las anteriores medidas se complementaron con la sugerencia del Gobierno a Ecopetrol de que los recur sos financier os que necesite este año, no los gestioneen el mercado externo, sino en el interno, es decir, que la entidad se endeude en pesos y no en dólares, para evitar la entrada de moneda extranjera que presiona la tasa de cambio al alza.

A lo largo del semestre, el banco central redujo la tasa de interés hasta situarla en un 3,25\% y ha mantenido la compra de 30 millones de dólares diarios, mientras quela tasa de cambio pasó de \$1.773 por dólar, a principios deenero, a 1.929 el 31dejunio, alcanzando un valor máximo de 1.942,97 el 24 de junio. Por ello, la devaluación en el semestre fue del 8.8\%, siendo más intensa en los meses de mayo y junio. Esta situación ha sido una característica de todos los países de América Latina, en los que la depreciación de sus monedas ha sido más fuerte en los tres últimos meses, hasta el punto que para dicho trimestre, el real brasileño se devaluó en cerca de $12 \%$, el sol peruano en un $10,7 \%$, el peso chileno en un $9,1 \%$ y el peso mexicano en un $8,7 \%$.

Esinteresantequeel periodo de mayor depreciación de lasmonedas latinoamericanas, coincide con tres aspectos importantes: en primer lugar, los precios de los commodities, a excepción del petróleo, han bajado; en segundo lugar, el crecimiento de China y de India, compradores destacados de materias primas, ha sido modesto , lo que explica, en parte, que el precio de las mismas haya bajado; en tercer lugar, las declaraciones del presidente de la Reserva Federal (banco central delos Estados Unidos), Ben Bernanke, en el sentido quesuspendería la política monetaria aplicada desde finales de 2008, consisten en ampliar la oferta monetaria, aportándole mensualmente a la economía de los EE.UU., 85.000 millones dedólares, lo queha llevado a quela tasa de interés esté cercana a cero.

A juicio de la Reserva Federal, la economía de EE.UU. se está recuperando, aunque ni la producción ni el empleo, hayan reaccionado en los niveles esperados. Los inversionistas entendieron las declaraciones de Bernanke, como que en el futuro próximo se reduciría la oferta monetaria y que eso llevaría a un incremento en la tasa de interés, lo cual conduciría a un fortalecimiento del dólar.

Al examinar la evolución de la tasa decambio en el primer semestre de este año, queda claro que los factor es externos son determinantes, y, es posible, quelas decisiones que tomen, tanto la Junta Dir ectiva del Emisor como el Gobierno, pueden afectarla. Hizo falta aplicar medidas más decidas como la de establecer controles al ingreso de capitales y al endeudamiento privado en dólares, para evitar una sustancial revaluación del peso. Empero, lo constatado en el mes de junio demuestra quelas decisiones de la Reserva Federal para influir en la tasa de interés,tendientes a fortalecer el dólar, tienen mayor peso que la intervención de los bancos centrales. Como lo plantea Eduar do Sarmiento, las declaraciones de Bernanke generaron una depreciación queno se había alcanzado en nueveaños.

LUISEUDORO VALLEJO ZAM UDIO Director de Apuntes del CENES 